\title{
Quality Of Life Among People With Type Ii Diabetes Mellitus
}

\author{
${ }^{1}$ Reena Evency.A., ${ }^{2}$ Feby.G. \\ ${ }^{1}$ Principal, ${ }^{2}$ Vice Principal, St. Xavier's Catholic College of Nursing. \\ DOI: 10.29322/IJSRP.11.11.2021.p11951 \\ http://dx.doi.org/10.29322/IJSRP.11.11.2021.p11951
}

Abstract

Type II Diabetes mellitus is a chronic disease that affects all parts of the body and causes serious potentially life threatening complications. The mere presence of diabetes deteriorates a person's quality of life. A study was conducted to assess the quality of life among 160 people with type II diabetes mellitus. Quantitative research approach with descriptive research design was adopted. Data collected through structured interview schedule using modified rating scale on quality of life for Indian Diabetes patients. The findings revealed that $99 \%$ had satisfactory quality of life, $1 \%$ had good quality of life and none had poor quality of life.

Keywords: Quality of Life, People with Type II Diabetes Mellitus, Complications.

\section{Introduction}

Type II Diabetes Mellitus is a lifelong metabolic threat in this contemporary era. The term diabetes was first used in 250 BC by the Greek Apollonius of Memphis. Diabetes type I and type II were recognized first time by the Indian physicians Sushruta and Charaka in $400-500$ BC. According to International Diabetes Federation (2017), 415 million people were affected worldwide i.e. one in every 11 adults has diabetes mellitus. $46.5 \%$ of adults were undiagnosed. By 2040 it is predicted that 642 million people in worldwide (i.e.) one in 10 adults may suffer with Diabetes Mellitus.

Type II diabetes was the fourth leading cause of death globally. Every fifth diabetic in the world is an Indian. People in Asia are extremely at risk compared to western countries due to the changes in the life style pattern and white rice intake. India is titled as the pre diabetes cattle of the world with an estimate of about 72.94 million in 2017.The number of people with Diabetes mellitus in India increased from 26.0 Million in 1990 to 65 million in 2016. Prevalence in 2016 was highest in Tamilnadu and Kerala according to the Global Burden of disease study, 2018.

Progression of diabetes mellitus and mainly poor glycemic control leads to numerous potentially life threatening complications. The Type II Diabetes Mellitus has a major impact on quality of life in terms of the various domains such as physical, social and mental wellbeing. Uncontrolled diabetes mellitus increases the health problems that may lead to reduced quality of Life.

Therefore assessing the quality of life is very much essential to identify the individual perception such as satisfaction and happiness. Disease management need to be assessed in the concept of quality of life. The quality of life and satisfaction are related to good glycemic control, self care practices, diet, good medical care and better quality of physical activity. There are limited studies to evaluate the quality of life among people with type II Diabetes mellitus. In order to fill that gap, this study was carried out to assess the quality of life among people with Type II diabetes mellitus.

\section{Statement of the problem}


A descriptive study to assess the quality of Life among people with Type II Diabetes Mellitus in a selected rural area at Kanyakumari District.

\section{Objectives}

- $\quad$ To assess the prevalence of people with Type II Diabetes Mellitus.

- To assess the quality of life among people with Type II Diabetes Mellitus.

- To find out the association between selected demographic variables among people with Type II Diabetes Mellitus with their quality of life.

- $\quad$ To find out the association between selected health related variables among people with Type II Diabetes Mellitus with their quality of life.

\section{Methodology}

Conceptual framework was based on health Belief model. Quantitative research approach with descriptive research design has been adopted. After obtaining formal permission from the Institutional ethical committee and medical officer of the selected rural area, the study was conducted. The accessible population was all the people with type II Diabetes Mellitus who fulfilled the criteria of sample selection. 163 people had been identified as people with Type II Diabetes mellitus among 2500 population. Three drop outs (males) during the data collection after survey. Hence the total sample size was 160 . The data collection tool consisted of two selections. Selection A dealt with the background variables in which Part I consisted of eight demographic variables and Part II consisted of 13 health related variables and section B dealt with the modified Likert scale on quality of life for Indian diabetes patients with 10 dimensions. Data collection done through structured interview schedule for 30 minutes.

\section{Results and discussion}

The findings of the study were discussed based on the objectives of the study.

\section{Demographic Variables}

The frequency and percentage distribution of demographic variables among people with type II diabetes mellitus, majority $52(32.5 \%)$ were between the age of $51-60 \mathrm{yrs}$,

$113(70.62 \%)$ were females, $135(84.37 \%)$ were married, 134 $(83.75 \%)$ were educated up to higher secondary school education, 148 (92.5\%) were Christians, 70 (43.75\%) of them belonged to joint family, $83(51.87 \%)$ of them were heavy workers and 67 (41.87\%) were earning between Rs. 500 - Rs 10,000/- per month.

\section{Health Related Variables}

The frequency and percentage distribution of health related variables among people with type II diabetes Mellitus, 38 $(23.75 \%)$ had the family history of diabetes mellitus with father, $148(92.5 \%)$ were non - vegetarians, $146(91.25 \%)$ were not having the history of smoking tobacco, 150 (93.75\%) had no history of drinking alcohol, 85(53.12\%) were performing regular physical exercise, $84(52.5 \%)$ had the duration of treatment between 1 - 5 years, $150(93.75 \%)$ were taking alternative remedies for diabetes mellitus, $135(84.37 \%)$ had no history of co - morbid illness, 80(50\%) were diagnosed to have type II diabetes mellitus between $0-5$ years, 71 (44.37\%) of them had no complications of Type II diabetes mellitus, 89 (55.62\%) of them had Type II diabetes mellitus with one complication, 122(76.25\%) of them had fatigue as the related symptoms, 120(75\%) had the body mass index between $18.5-24.99$. 
The first objective of the study was to assess the prevalence of people with type II diabetes mellitus.

Assessment on prevalence of people with Type II diabetes mellitus

Table 1: Over all Prevalence of people with type II diabetes Mellitus

\begin{tabular}{|c|c|c|c|c|c|c|c|c|}
\hline \multirow[t]{2}{*}{$\begin{array}{l}\text { No. of People } \\
\text { Screened }\end{array}$} & \multicolumn{2}{|c|}{$\begin{array}{l}\text { Age } \\
\text { (in years) }\end{array}$} & \multicolumn{2}{|c|}{ Overall Prevalence } & \multicolumn{2}{|c|}{$\begin{array}{l}\text { Prevalence among } \\
\text { Males }\end{array}$} & \multicolumn{2}{|c|}{$\begin{array}{l}\text { Prevalence among } \\
\text { Females }\end{array}$} \\
\hline & From & To & f & $\%$ & f & $\%$ & $\mathbf{f}$ & $\%$ \\
\hline 2500 & 40 & 80 & 163 & 6.52 & 50 & 2 & 113 & 4.52 \\
\hline
\end{tabular}

The overall prevalence of people with Type II diabetes mellitus in the selected rural areas were 163 among 2500 population. The gender specific prevalence was higher among 69.32\% (113) females than 30.68\% (50) males.

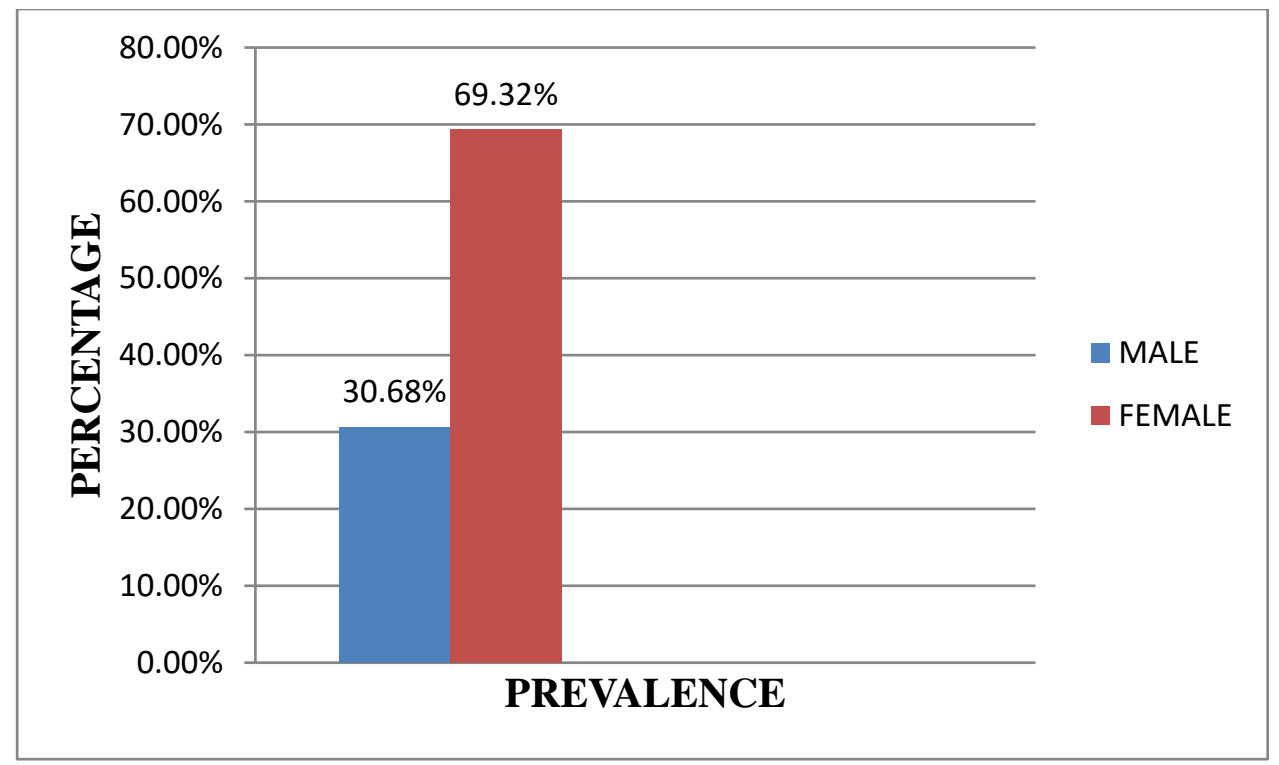

Figure 1: Bar chart representing the Gender specific prevalence of people with Type II Diabetes mellitus.

The second objective of the study was to assess the quality of life among people with type II diabetes mellitus.

Assessment on quality of life among people with Type II diabetes mellitus

Table 2: Mean and standard deviation on quality of life among type II diabetes Mellitus

\begin{tabular}{|l|l|l|l|c|}
\hline Quality of life & Frequency (f) & $\begin{array}{l}\text { Percentage } \\
(\%)\end{array}$ & Mean & $\begin{array}{l}\text { Standard } \\
\text { deviation }\end{array}$ \\
\hline Good & 2 & 1 & \multirow{2}{*}{111} & \pm 8.41 \\
\cline { 1 - 3 } Satisfactory & 158 & 99 & & \\
\hline Poor & 0 & 0 & & \\
\hline
\end{tabular}


The overall frequency and percentage distribution on quality of life among people with Type II diabetes mellitus were $2(1 \%)$ had good quality of life, $158(99 \%)$ had satisfactory quality of life and none had poor quality of life.

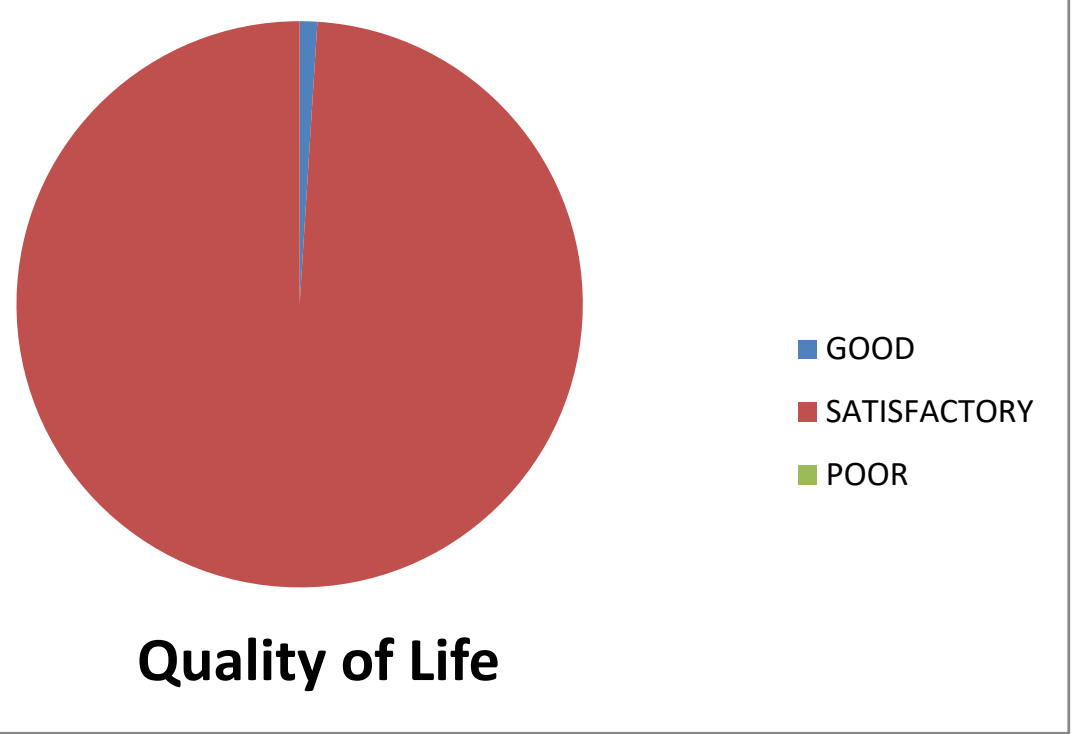

Figure 2: Pie-chart representing the overall quality among People with Type II Diabetes mellitus

Assessment on quality of life based on the dimensions among people with Type II diabetes mellitus.

The frequency and percentage distribution on quality of life based on the dimensions among people with type II diabetes mellitus.

In role limitation due to physical health, 148 ( 93\%) had satisfactory quality of life, physical endurance $131(82 \%)$ had satisfactory quality of life, general health 131(82\%) had satisfactory quality of life, symptom botherness 153 (96\%) has satisfactory quality of life, emotional/ mental health 126 (78\%) had - satisfactory quality of life, dietary advice tolerance 116 (73\%) had satisfactory quality of life, degree of freedom 108(68\%) had satisfactory quality of life, environment $82(51 \%)$ had satisfactory quality of life, financial worries 122(76\%) had satisfactory quality of life, treatment satisfaction 99 (62\%) had satisfactory quality of life. 


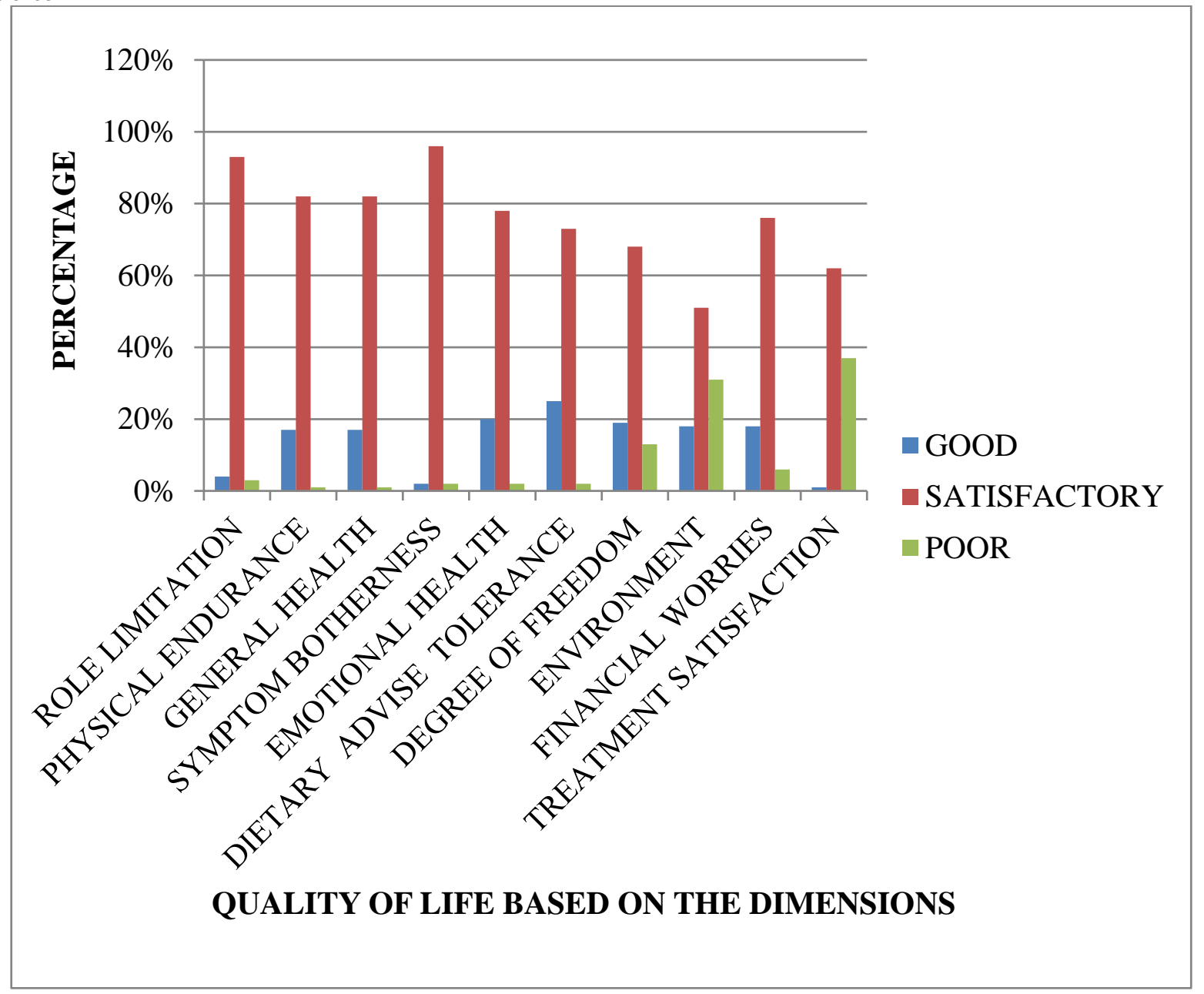

Figure 4: Grouped bar chart representing the quality of life based on the dimensions.

Table 3: Mean and standard deviation on quality of life based on the dimensions among people with type II diabetes Mellitus

\begin{tabular}{|l|l|l|}
\hline Quality of life & Mean & Standard deviation \\
\hline Role limitation due to physical health & 13.93 & \pm 2.24 \\
\hline Physical endurance & 15.95 & \pm 2.78 \\
\hline General health & 12.50 & \pm 1.36 \\
\hline Symptom botherness & 8.70 & \pm 1.07 \\
\hline Emotional/ mental health & 13.27 & \pm 3.30 \\
\hline Diet advises tolerance & 8.56 & \pm 1.85 \\
\hline Degree of freedom & 9.12 & \pm 1.91 \\
\hline Environment & 5.29 & \pm 2.25 \\
\hline Financial worries & 13.57 & \pm 3.31 \\
\hline Treatment satisfaction & 10.56 & \pm 4.25 \\
\hline
\end{tabular}


The above findings were congruent with a cross-sectional study conducted by

Majeed .I, Afzal. M, Sehar. S, Gilani. S.A , Alam. M.M (2019) on quality of life among 180 patients with Type II Diabetes mellitus admitted in a tertiary care centre. Findings of the study revealed that the mean Quality of life score of type-II diabetics was 51.8. Score on various domains indicating the Quality of Life among type-II diabetics was 55\% in physical, $47 \%$ in psychological, 55\% in social and $50 \%$ in environmental domain. The overall domain wise scoring revealed an average Quality of Life.

The third objective of the study was to find out the association between demographic variables among people with Type II diabetes mellitus with their quality of life

The findings revealed that there was no association between demographic variables such as age, gender, marital status, education, religion, type of family, occupation, family monthly income and their quality of life among people with Type II Diabetes mellitus.

The fourth objective of the study was to find out the association between health related variables among people with Type II diabetes mellitus with their quality of life

The findings revealed that there was a statistically significant association between habit of alcoholism $(\chi 2=21.410$, $\mathrm{p}<0.000)$, complications of diabetes mellitus $\left(\chi^{2}=22.770, \mathrm{p}<0.001\right)$ with their quality of life. There was no association between health related variables such as family history of diabetes mellitus, diet, exercise, habit of tobacco smoking, duration of treatment, duration of illness, body mass index, alternative treatment and quality of life among people with Type II diabetes mellitus.

The above findings were supported with a cross sectional study conducted by

Reeni. J, Sanjivani P, Leena C, and Prasanna R. D. (2019) on evaluation of quality of life in Type II Diabetes mellitus Patients using Quality of Life Instrument for Indian Diabetic Patients and found out a Statistically significant $(P<0.05)$ association between duration of treatment and complications with their quality of Life.

\section{Conclusion}

The present study is one among few studies in utilizing an Indian instrument. Identification of the Quality of life among people with type II diabetes mellitus related studies are very much essential for our country to explore the physical, social, mental, wellbeing, environment, and treatment satisfaction that may help the policy makers to plan accordingly to improve the quality of life among people with type II diabetes Mellitus.

\section{Acknowledgement}

This study has been conducted as a part of The Tamilnadu Dr.MGR Medical University,Chennai.

\section{References}

- $\quad$ Excel spread sheet to calculate Instrument Reliability estimates educational research basics by Del single. 2017 (Last accessed on 2018 Aug 31). http//www.researchbasics.education. comm.edu/excel. Spread sheet - to - Calculate instruments - St.

- $\quad$ Fernandes J, Ogurtsova K, Linnenkamp U Guariguata. L. Securing T, Zhang P, Cavan.D et.al, (2016) Diabetes atlas estimates of 2014 global health expenditures on Diabetes. Diabetes Res Clin Practice, 117.

- Hinkle.J.L., Cheever.K.H. (2016) Brunner \& Suddarth's Textbook of Medical Surgical Nursing. (13 ${ }^{\text {th }}$ Ed.).Vol. (II). Wolters Kluwer pvt Ltd, New Delhi.1419-1425. 
- Joha.R., Pise.S., Chaudhari.L., Prasanna.R., Desh pande.(2019).Evaluation of Quality of Life in Type II Diabetes mellitus patients using quality of life Instruments for Indian Diabetes patients: A cross sectional study, Journal of midlife health, April - June, 10(2): 81-88.

- Kumar P, Krishna. M. (2015). Quality of Life in Diabetes Mellitus. Science Journal of public health.3 (3).doi:10.11648/j.sjph20150303.12.

- Koshy J. (2020). prevalence of diabetes among women high in Southern India, CDC.

- Sri G. S, Kavitha H R, Reddy V. J Anil K (2015) Evaluation of Anti Diabetic therapy, Outcomes and Impact of patient Counselling on Quality of Life in type II Diabetes mellitus in a tertiary care teaching hospital. Indo American Journal of Pharm Science, 2, $810-877$. 